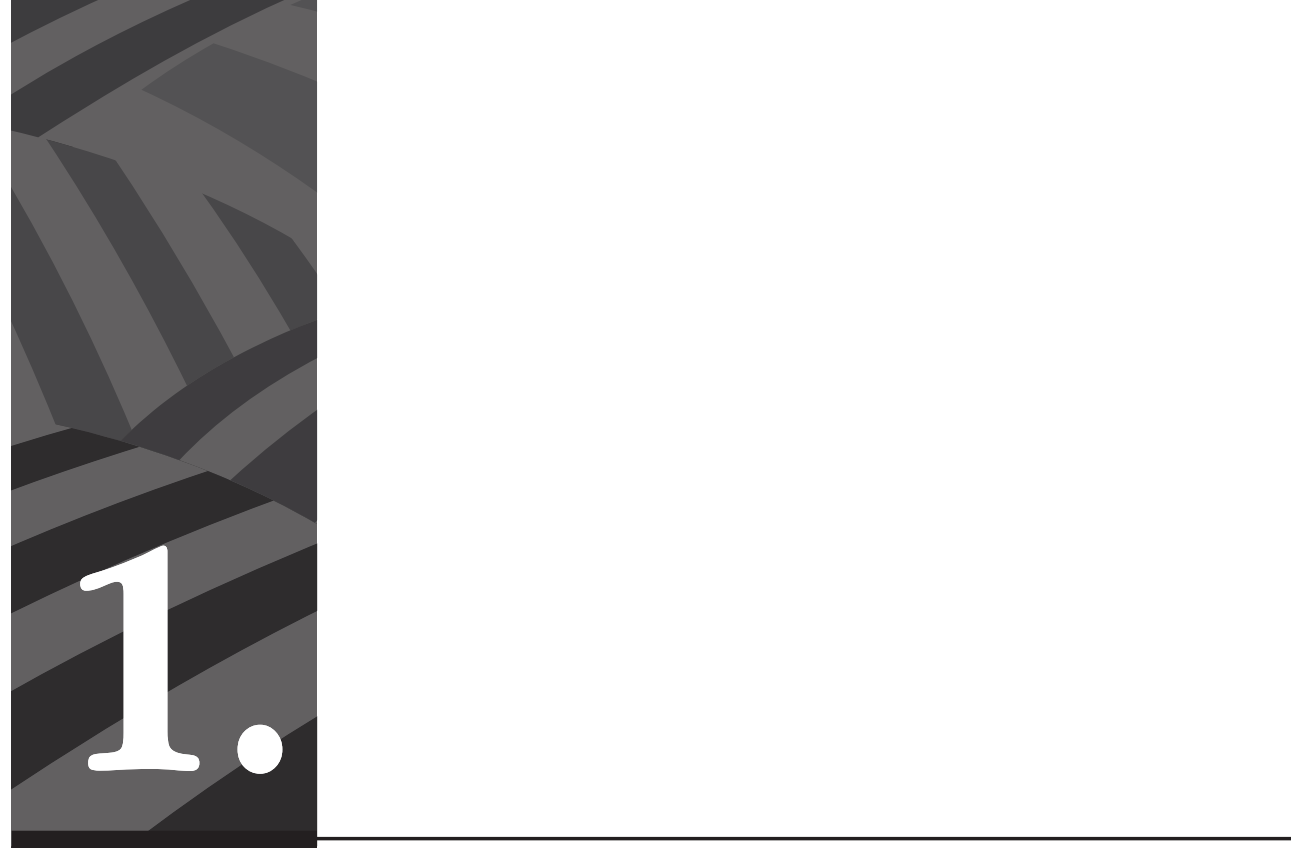

Las apuestas étnicas por la paz: antagonismos democráticos y diálogos sociales reticulares 


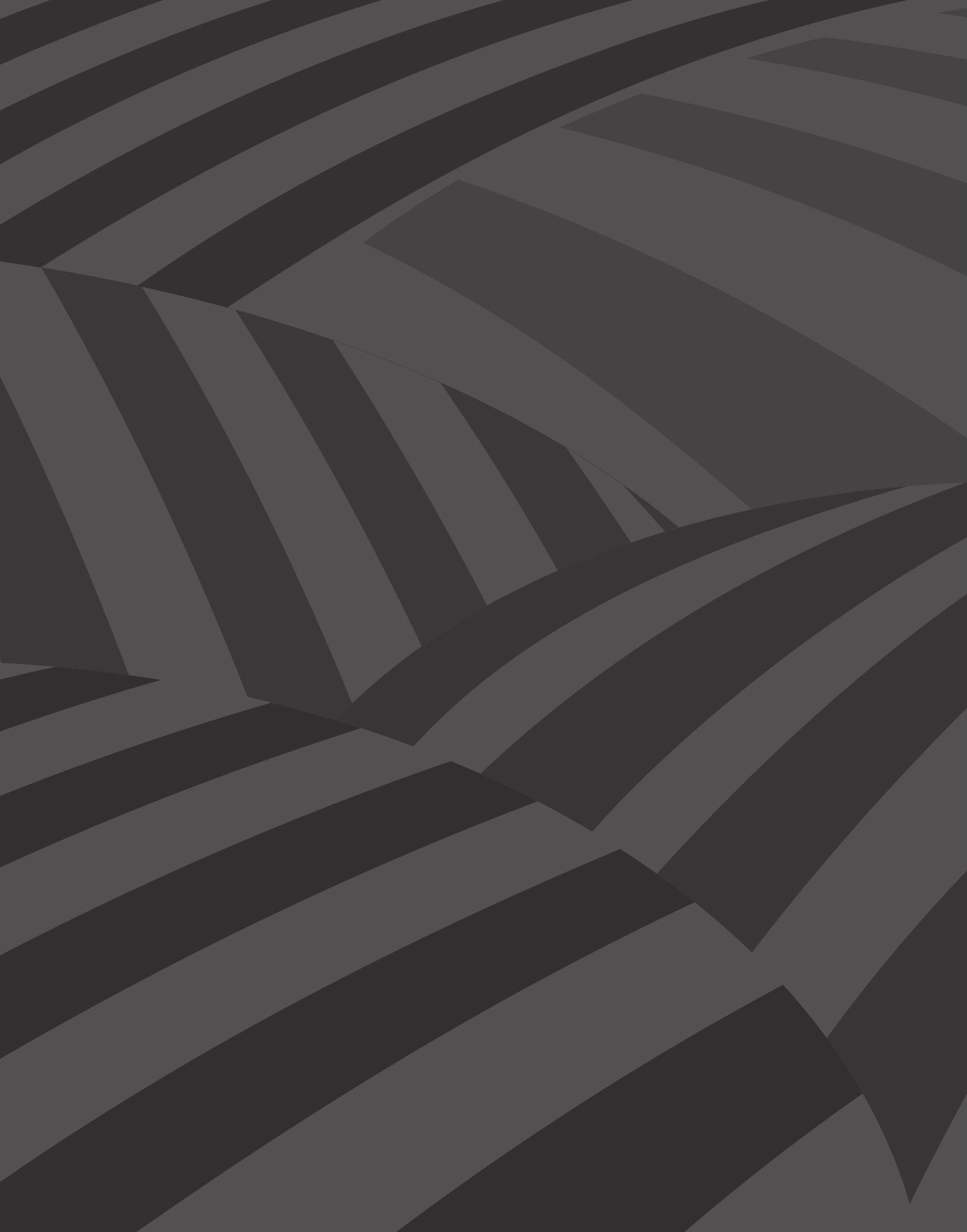




\section{Las apuestas étnicas por la paz: antagonismos democráticos y diálogos sociales reticulares ${ }^{1}$}

Por John Edison Sabogal Venegas*

Resumen: Este artículo presenta una reconstrucción interpretativa de la incidencia de las organizaciones indígenas y afrodescendientes en el proceso de negociación de paz de La Habana. A partir del análisis de los diferentes repertorios de acción y de las dinámicas antagónicas que los liderazgos étnicos construyeron para hacer visibles sus demandas y propuestas, se propone una reflexión sobre las posibilidades que brindan los diálogos sociales reticulares para la construcción de paz. Reconociendo el rol de las articulaciones políticas que condujeron a nivel nacional a la conformación de la Comisión Étnica, y prestando igual atención a los procesos locales y regionales en zonas claves como el norte del Cauca, el texto propone algunas dimensiones para pensar diálogos sociales reticulares como impulsores de transformaciones, a partir de antagonismos democráticos y deliberativos.

Palabras claves: construcción de paz, antagonismo, articulación, diálogos reticulares.

\section{Ethnic Perspectives on Peace: Democratic Antagonisms and Reticular Social Dialogues}

Abstract: This article presents an interpretive reconstruction of the influence of indigenous and afro-descendant organizations in the Havana peace negotiation process. Based on the analysis of the different repertoires of action and the antagonistic dynamics constructed by ethnic leaders to make their demands and proposals more visible, a reflection is proposed on the possibilities offered by reticular social dialogues for the construction of peace. Recognizing the role of the political articulations that led at the national level to the formation of the Ethnic Commission and

1 Texto basado en el trabajo de grado para obtener el título de máster en Études Politiques de la École des Hautes Études en Sciences Sociales (EHESS), París-Francia.

* Antropólogo y psicólogo de la Universidad Nacional de Colombia. Master en Estudios Políticos de la École des Hautes Études en Sciences Sociales (EHESS). Correo electrónico: joesabogalve@unal.edu.co 
paying equal attention to local and regional processes in key areas such as northern Cauca, the text proposes some dimensions for thinking about reticular social dialogues as promoters of transformations based on democratic and deliberative antagonisms.

Keywords: construction of peace, antagonism, articulation, reticular dialogues.

Cómo citar este artículo: Sabogal Venegas, John Edison (2020). Las apuestas étnicas por la paz: antagonismos democráticos y diálogos sociales reticulares. Revista Controversia, 214, 15-48.

Fecha de recepción: 30 de octubre de 2019

Fecha de aprobación: 16 de diciembre de 2019

\section{Introducción}

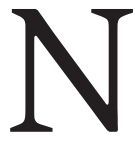

os enfrentamos, como sociedad colombiana, a un periodo convulso. Las esperanzas que abrió el acuerdo de paz firmado entre el Estado y las Fuerzas Armadas Revolucionarias de Colombia (FARC) siguen siendo interpeladas por las complejas mutaciones y continuidades que plantean todas las transiciones políticas (Castillejo, 2017). En un contexto en el cual la implementación de los acuerdos sufre grandes inconvenientes en temas sensibles como la reintegración de excombatientes y las reformas estructurales sobre la tierra (Kroc Institute, 2018), al tiempo que la violencia armada se reconfigura en los territorios dejados por la guerrilla, parece imperiosa la idea de Walter Benjamin (2009) de organizar el pesimismo. Vale la pena preguntar de qué manera es posible reencantar la imaginación política y vitalizar las esperanzas en la construcción de paz, reinventar los diálogos sociales y recrear conversaciones generativas, en medio de ciclos de violencia que en muchos territorios dan la sensación de no terminar. Una alternativa, de las muchas posibles, es volver sobre lo caminado para buscar entenderlo de otra manera. Reinterpretar los diálogos pasados y sus pliegues menos explorados para proyectar formas presentes y futuras de encuentro. Bajo esa intención, proponemos una relectura de los diálogos de paz desde el punto de vista de las organizaciones indígenas y afrodescendientes, que lograron, al límite de la firma del acuerdo entre las FARC y 
el Gobierno, el reconocimiento explícito de sus derechos en lo que se denominó el capítulo étnico.

Este capítulo especial del acuerdo incluye al menos tres dimensiones: un conjunto de reconocimientos históricos, unas garantías a través de salvaguardas de derechos étnicos previamente alcanzados y finalmente unas disposiciones concretas en el marco de la implementación del acuerdo (Braconnier, 2018). Reconstruir los diferentes momentos de la lucha afro e indígena por visibilizar sus propuestas de paz en las negociaciones de La Habana, nos permite reflexionar sobre cómo los diálogos sociales están inscritos en antagonismos que pueden ampliar los términos y las posibilidades de la conversación. Adicionalmente al concepto de antagonismo, propondremos la noción de diálogos sociales reticulares para acentuar la forma rizomática que las reivindicaciones y acciones políticas de los movimientos sociales pueden tomar (Karatzogianni y Robinson, 2010), prestando atención tanto a las acciones colectivas de alcance nacional e internacional como especialmente a los referentes territoriales de dichos procesos de movilización (Merklen y Pleyers, 2011).

En concreto, nos interesa reconocer y reflexionar sobre los aprendizajes que deja la incidencia étnica en las negociaciones de La Habana como antagonismo potencializador de un diálogo más amplio sobre el significado y la práctica de la construcción de paz. Al analizar los diferentes momentos y estrategias de la acción colectiva étnica en sus apuestas por participar en los acuerdos de paz, quisiéramos resaltar tres aspectos que pueden vitalizar futuros diálogos sociales. Primero, el entretejido de diferentes planos de acción con una fuerte raíz en lo local, que escalan a lo regional y nacional sin descartar incluso el ámbito internacional, una expresión de lo que llamamos diálogos sociales reticulares. Una hipótesis es que, dada la importancia de las experiencias territoriales en las apuestas étnicas de paz, un nodo de acción colectiva étnica ha sido el Cauca y particularmente el norte del departamento, por su tradición 
de resistencia (Peñaranda, 2015) y por ser locus, referente y desencadenador de luchas y movilizaciones contemporáneas. En segundo lugar, resaltamos la creación, en el 2016, de la Comisión Étnica para la Paz y la Defensa de los Derechos Territoriales (en adelante Comisión Étnica) como un ejemplo interesante de articulación política entre el movimiento indígena y el afrodescendiente, que amplificó diálogos interétnicos e interculturales precedentes (Vega, 2019). Finalmente, el tercer aspecto que quisiéramos señalar es que, en el antagonismo democrático de las organizaciones étnicas ante el estrecho margen de participación en La Habana, indígenas y afros posicionaron significados que sintetizan las históricas tensiones de estos movimientos sociales con el Estado y con las insurgencias, interpelando el significado hegemónico de la paz que se construía por las FARC y el Gobierno.

Desde la victoria del No en el plebiscito y tras el comienzo de la implementación del acuerdo final firmado en noviembre del 2016, el proceso de paz ha vivido años de prueba, en el doble sentido de la palabra. Prueba en términos de desafío, de reto para concretar posibilidades reales de transformación de los problemas estructurales que han desencadenado y reproducido la violencia. A su vez, prueba en el sentido de constatación o evidencia de las complejidades que encarna un momento de transición política, de las mutaciones del conflicto armado, pero a su vez de la importancia de las apuestas territoriales y organizativas para la construcción de paz. Los diálogos de La Habana fueron sin duda un momento de clivaje, toda vez que posibilitaron la discusión de problemas estructurales, movilizaron diferentes sectores sociales alrededor de los acuerdos y permitieron imaginar salidas negociadas a la violencia armada tras fallidos intentos de negociación con esa misma guerrilla (Villarraga, 2015). Marcados por diferentes altibajos políticos, en un ambiente creciente de polarización y de ataques de sectores conservadores que perduran hasta el momento, sectores sociales como las víctimas, mediante sus apuestas y su participación en el proceso, tuvieron un papel clave en las discusiones de La Habana (Brett, 2017; 2018). Una relectura de ese momento histórico, a partir de una reconstrucción 
interpretativa de la participación contestataria de las organizaciones étnicas, nos permitirá reflexionar sobre las características y los aprendizajes que deja esta experiencia. Nos interesa prestar especial atención al propio significado que las organizaciones y liderazgos étnicos dieron a este momento, por lo cual acudimos a dos fuentes principales. Por un lado, el análisis de fuentes secundarias, especialmente de comunicados emitidos por las organizaciones étnicas, así como documentos públicos de las negociaciones entre las FARC y el Gobierno. En segundo lugar, la realización de 27 entrevistas a diferentes líderes y lideresas afros e indígenas $^{2}$ alrededor de su participación en los diálogos de paz.

Una de las ideas centrales que buscamos argumentar es que la participación étnica en las conversaciones de La Habana es un ejemplo paradigmático de diálogo social contestatario, que involucró la creación de consensos interétnicos y el posicionamiento de un antagonismo democrático frente a la indiferencia del Gobierno y las FARC sobre lo étnico. Para abordar este asunto, nos interesa preguntarnos por cómo las apuestas étnicas por la paz se hicieron visibles a lo largo de las negociaciones de La Habana, posicionando antagonismos sin bloquear el diálogo social. A su vez, buscamos identificar cuáles fueron las estrategias de las organizaciones étnicas para visibilizar sus demandas, y a partir de allí reflexionar sobre cuáles pueden ser las relaciones entre acciones colectivas, antagonismos democráticos y diálogos reticulares en pro de la construcción de paz. En un primer momento reconstruiremos de forma sintética la participación étnica en los diálogos de

2 Las y los líderes entrevistados hacen parte de organizaciones locales y regionales, principalmente del norte del Cauca, así como de organizaciones nacionales y miembros de la Comisión Étnica. Algunos de los miembros de organizaciones étnicas entrevistados hacen parte de la Asociación de Cabildos Indígenas del Norte del Cauca (ACIN), el Consejo Regional Indígena del Cauca (CRIC), la Asociación de Consejos Comunitarios del Norte del Cauca (ACONC), el Palenque Alto Cauca del Proceso de Comunidades Negras (PCN), la Asociación Nacional de Afrocolombianos Desplazados (AFRODES), la Organización Nacional Indígena de Colombia (ONIC), Gobierno Mayor, entre otras. La mayor parte de las entrevistas fueron realizadas durante el segundo periodo del 2018 y unas pocas se realizaron en el 2016. 
La Habana, prestando especial atención a los repertorios de acción colectiva más allá de los espacios formales, mediante los cuales indígenas y afros hicieron visibles sus demandas. Posteriormente, reflexionaremos sobre los factores nodales que posibilitaron que luego de años de insistencia, las organizaciones étnicas fueran escuchadas y lograran concertar un capítulo especial en el acuerdo final de paz, así como argumentaremos la importancia de los liderazgos y organizaciones étnicas del norte del Cauca en este proceso. Finalmente, a manera de síntesis comprensiva, señalaremos algunos elementos centrales que emergen como aprendizajes de estas experiencias y enriquecen las posibilidades actuales y futuras de los diálogos reticulares sobre la paz, reconociendo los antagonismos y posibilitando las articulaciones políticas.

\section{Las reivindicaciones étnicas: momentos de un antagonismo}

Desde el inicio mismo de las negociaciones, organizaciones afros e indígenas de carácter regional y nacional exigieron a las partes involucradas una participación efectiva y directa para ser escuchadas. Su exigencia era argumentada no solo por los fuertes impactos que ha dejado la guerra en sus comunidades y territorios, sino también por sus experiencias y apuestas territoriales de paz. Indígenas y afros reivindicaron — primero cada uno desde sus espacios y luego articuladamente- su papel como colectividades políticamente activas en la construcción de una salida negociada al conflicto. A medida que las negociaciones avanzaban y se hacían públicos los acuerdos parciales en los puntos de la agenda, lo que significaban como exclusión de La Habana suscitó múltiples preocupaciones. Como lo menciona un líder afro entrevistado: "Cuando crearon la mesa, al comienzo, lo mirábamos como una oportunidad de participación y luego, a los tiempos, a los meses que nos negaron la participación, se convirtió en una amenaza”. Dos grandes problemáticas comenzaron a perfilarse como fuentes de preocupación. Por un lado, lo que denominamos problema de potencial regresividad de derechos colectivos obtenidos luego de décadas de reivindicaciones. 
Para varias organizaciones étnicas, la exclusión de las negociaciones y la falta de garantías en ciertos puntos de lo acordado entre FARC y Gobierno, podrían ser una amenaza a sus derechos territoriales, a la autonomía, al derecho a la consulta y en últimas a su bienestar en el marco del posacuerdo.

Ligado a esto, la segunda fuente de preocupación fue el problema de representatividad, bajo el cual indígenas y afros argumentaban que no estaban representados en los diálogos de paz ni por el Gobierno ni por las FARC, y que los espacios formales de participación creados eran insuficientes para plantear su voz. Varios líderes y lideresas entrevistadas mencionaron que veían en la agenda "campesinista" de las FARC ciertos aspectos conflictivos con los derechos étnicos, por ejemplo, frente a los derechos territoriales y los posibles solapamientos en la conformación y delimitación de nuevas Zonas de Reserva Campesina (ZRC) (Caballero-Fula, 2016). En palabras de un líder indígena entrevistado: "El enfoque en que insistieron mucho las FARC es un enfoque desde una visión campesina, que es una visión política que tienen las FARC en sus reivindicaciones desde su nacimiento hasta la fecha, independientemente que tuvieran indígenas y afros en sus filas”.

Formalmente y con el fin de escuchar las propuestas de la sociedad civil, las FARC y el Gobierno establecieron cuatro mecanismos de participación: foros temáticos en Colombia sobre cada uno de los puntos de la agenda, delegaciones de víctimas en La Habana, recepción de propuestas por medios virtuales y, luego de concretarse la primera versión del acuerdo, el plebiscito de refrendación (Oficina del Alto Comisionado para la Paz, 2018). Desde la perspectiva de las organizaciones étnicas, dichos espacios resultaron insuficientes para que sus propuestas y demandas frente a la paz fueran escuchadas. Por ejemplo, desde los primeros foros las organizaciones étnicas sintieron que la metodología no les permitía plantear sus posiciones como colectividad, por lo cual en un comunicado las organizaciones afro que participaron en el primer foro afirmaron: "Haremos nuestra mesa e invitamos a todos los afro- 
colombianos, y a los que también lo deseen, a desobedecer la tiranía de la metodología” (Organizaciones afrocolombianas, 2016, p. 363). La apuesta era participar como colectividades y organizaciones, es decir, no solo como víctimas individuales, con el objetivo de plantear directamente sus preocupaciones y discutir sus propuestas con el Gobierno y con las FARC. En un ejercicio de participación contestataria que articulaba capacidad de diálogo y acciones de confrontación, indígenas y afros comenzaron a abrir espacios más allá de los medios formales, con el fin de ser escuchados. Por participación contestataria entendemos las estrategias colectivas y democráticas que sobrepasan los escenarios formales e institucionales, donde los ciudadanos posicionan sus demandas y apuestas políticas en contextos potencialmente conflictivos. ${ }^{3}$ Aunque conceptualmente se acerca a la noción de política contenciosa y sus dos variaciones - la contingente y la transgresiva-, propuestas por Mcadam, Tarrow y Tilly (2003), consideramos que la centralidad de la autonomía territorial defendida desde hace décadas por indígenas y afrodescendientes va mucho más allá de la unidireccionalidad entre sociedad y Estado que subyace a la dinámica de contención.

\section{Dinámicas antagónicas y repertorios de acción}

Analíticamente podemos identificar cinco dinámicas antagónicas que ocurrieron en el trascurso de los diálogos de La Habana, en las que se hace evidente la incidencia de las organizaciones étnicas en las negociaciones de paz. Cada dinámica nos permite reflexionar sobre la importancia que tienen los antagonismos democráticos y las acciones colectivas respecto a ampliar los horizontes de los diálogos sociales en determinados momentos históricos. Más que situaciones cronológicamente ordenadas, nos interesa señalar las reivindicaciones y lógicas de lo político que involucran cada uno de dichos antagonismos. La primera dinámica fue la concreción de agendas particulares

3 Nos referimos principalmente a la conflictividad política, pero también a la armada, territorial, cultural, etc. 
donde indígenas y afros formalizan — cada uno en sus espacios - sus propuestas para la paz. En segundo lugar, las denuncias públicas de la situación humanitaria vivida en sus territorios y la exigencia de respuestas por parte de la guerrilla y el Estado. Posteriormente, una reinterpretación de su participación desde y más allá del ser víctimas, ampliando dicho significante y anclándolo a reivindicaciones históricas. Como cuarta dinámica antagónica, identificamos la articulación política de la Comisión Étnica, la cual, más que inédita, es una forma de expresión de diálogos sociales que desde hace décadas se han establecido en diferentes momentos entre organizaciones indígenas y afros, y en otras ocasiones con otros sectores sociales como campesinos y estudiantes. Finalmente, un quinto conjunto de dinámicas que involucran acciones de movilización, diplomacia y presión para abrir espacios de diálogo directo con los negociadores de La Habana.

Desde nuestro análisis, la apertura del diálogo con las organizaciones étnicas para la concreción del capítulo étnico ocurrió gracias al antagonismo - parcial y democrático — de afros e indígenas frente al discurso hegemónico de la paz construido por el Gobierno y las FARC desde La Habana. Por antagonismo parcial señalamos una diferencia trascendental con el antagonismo total que los sectores políticos conservadores han manifestado en relación a las negociaciones y los acuerdos con la guerrilla. El antagonismo étnico no era una oposición a una salida negociada al conflicto, exigencia que las mismas organizaciones han hecho desde hace décadas, ni tampoco fue un rechazo absoluto a los avances o a lo acordado. Dicho antagonismo era un rechazo a la posible exclusión de su participación y al no reconocimiento explícito de sus derechos, en otras palabras, un antagonismo a la indiferencia de lo étnico en los acuerdos. Conceptualmente, Laclau y Mouffe (1987) aseguran que los antagonismos son parte consustancial de las sociedades y de lo político. Desde su perspectiva, "cualquier posición en un sistema de diferencias, en la medida en que es negada, puede constituirse en sede de un antagonismo" (Laclau y Mouffe, 1987, p. 151). Justamente, dos de los núcleos transversales del antagonismo étnico fueron, como lo men- 
cionamos, la necesidad de autorrepresentarse y la exigencia de respeto a los derechos históricamente conseguidos luego de siglos de luchas indígenas y afros. En el caso de las organizaciones étnicas, su antagonismo democrático, dialogante y a la vez contestatario, les permitió ser escuchadas y participar activamente en el proceso de paz.

Reconstruyamos sintéticamente, desde la significación de los propios actores sociales, las lógicas antagónicas de las cinco dinámicas señaladas. La primera involucra la construcción de agendas étnicas particulares, donde las principales organizaciones nacionales y regionales indígenas y afros, cada una en sus espacios y desde sus propias apuestas, formalizaron sus demandas frente a la paz. Por ejemplo, el movimiento afrocolombiano creó en el 2014 el Consejo Nacional de Paz Afrocolombiano (CONPA), ${ }^{4}$ con el fin de articular diferentes organizaciones alrededor de la paz. Los cinco componentes estratégicos planteados fueron: 1) territorios como espacios vitales para el buen vivir; 2) paz con justicia social y defensa de derechos económicos, sociales y culturales; 3) reconocimiento del etnocidio, derechos de las víctimas y reparación étnica colectiva; 4) racismo estructural, discriminación y enfoques diferenciales; y 5) autonomía, participación y gobernabilidad propia a partir del fortalecimiento del movimiento social afro (CONPA, 2017). Por su parte, el movimiento indígena hizo pública una Agenda Nacional de Paz Indígena, liderada por la ONIC (2015). A partir de la realización de encuentros macrorregionales a finales de noviembre del 2014 y un Foro Nacional realizado a principios de 2015, la agenda indígena planteaba incidir efectivamente en la negociación de La Habana, posicionando reivindicaciones históricas como tierras y territorios, autono-

4 Las organizaciones que hacen parte del CONPA son: Autoridad Nacional Afrocolombiana (ANAFRO), Proceso de Comunidades Negras (PCN), Asociación Nacional de Afrocolombianos Desplazados (AFRODES), Asociación de Consejos Comunitarios del Norte del Cauca (ACONC), Foro Interétnico de Solidaridad Chocó (FISCH), Grupo de Género Afro, Conferencia Nacional de Organizaciones Afrocolombianas (CNOA), Consejo Laboral Afrocolombiano (CLAF), Red Nacional de Mujeres Afrocolombianas "KAMBIRI” y Pastoral Afrocolombiana Chocó. 
mía, participación política étnica, respeto a los derechos humanos y al derecho internacional humanitario (DIH), así como reparación integral a las victimizaciones del conflicto. Tres aspectos en común podemos enfatizar en esta formalización de las agendas de paz: la búsqueda de participación directa en la mesa de negociación; la exigencia de respeto a los territorios colectivos y a la autonomía; y la exigencia de que los acuerdos no afectaran a las comunidades. Dentro de los énfasis particulares se encuentran, por ejemplo, las reivindicaciones contra el racismo estructural en el caso afro y el reconocimiento de la justicia propia en el caso indígena.

Un segundo motor del antagonismo étnico fue la situación humanitaria de los territorios, dados los hechos que experimentaban las comunidades en momentos en que la confrontación armada escalaba durante las negociaciones, principalmente en el 2012 y 2013. La exigencia del cese al fuego bilateral y definitivo estuvo presente en diferentes comunicados y como parte de la agenda de varias movilizaciones, como ocurrió, por ejemplo, en el paro agrario del 2013 (Cruz, 2017). Para incidir en este punto, el Cauca y en particular sus organizaciones indígenas fueron claves, pues decidieron establecer contacto directamente con los comandantes de las FARC en La Habana, hacia finales del 2014, para exigir el respeto a las comunidades y la interrupción de la presión armada expresada en combates, amenazas y asesinatos de líderes. En particular, la ACIN fue una de las organizaciones pioneras en dicho contacto, que luego fue respaldada por el CRIC y la ONIC con el fin de interpelar a los negociadores de la guerrilla, logrando un documento de compromiso y respeto en diciembre del 2014 (Vega, 2019). En palabras de un líder indígena del norte del Cauca que recuerda dicho momento:

Había un contexto de violación de derechos humanos, de asesinatos a líderes, de enfrentamientos y hostigamientos en el territorio por las FARC, ya era una guerra exacerbada digamos. Nosotros habíamos pensado en un acuerdo humanitario entre las FARC y el movimiento indígena [...] un acuerdo humanitario para evitar más asesinatos. 
La centralidad de los liderazgos indígenas del norte del Cauca en esta dinámica antagónica, de oposición directa a la guerra, se explica no solo por el fuerte impacto del conflicto en esta región, sino también por la larga y conflictiva relación entre el movimiento indígena caucano y las FARC, agudizada desde los ochenta con la exigencia por parte del CRIC de la salida de todos los grupos armados. Un antecedente de esta interpelación directa a los comandantes de las FARC y el logro de un acuerdo humanitario ocurrió en los diálogos de paz de La Uribe (Meta), a finales de los ochenta (Navia Lame, 2015; Vega, 2019).

La tercera dinámica de antagonismo ocurre alrededor de la participación desde y más allá del ser víctima. En una búsqueda por legitimar su voz en La Habana, indígenas y afros sobrepasaron la noción canónica de víctima como sujeto individual afectado por la guerra y destinatario inactivo de reparación, resignificando política e históricamente esta categoría. En diferentes contextos globales, la condición de víctima se ha movilizado ante las sociedades y los Estados como fuente de demandas políticas y de derechos garantizados solo tras el reconocimiento público del sufrimiento (Gatti y Martínez, 2017; Gatti, 2017). Autores como Druliolle y Brett (2018) denominan “políticas de la victimización” justamente a los procesos de definición, negociación y confrontación de los significados sobre la noción de "víctima” que ocurre entre los diferentes actores involucrados. Como construcción social, la victimización y la categoría de víctima se configuran en la interacción entre diferentes actores, criterios, prácticas y significados, involucrando cómo las víctimas se ven a sí mismas y cuál es la visión de los otros sobre ellas. En procesos de justicia transicional y de construcción de paz, la noción de víctima es "la categoría definitoria de aquellos actores que demandan verdad, justicia y memoria en escenarios de posconflicto” (Druliolle y Brett, 2018, p. 4 traducción libre).

Desde nuestra perspectiva, uno de los mayores aprendizajes que puede proporcionar la experiencia indígena y afrodescendiente en su incidencia en los diálogos de paz es el ejercicio de resignificación que 
elaboraron como grupos victimizados para aportar al proceso de paz, interpelando las categorías bajo las cuales se entiende la transición. Puesto que las FARC y el Gobierno aseguraban que las víctimas estarían en el centro del acuerdo, las organizaciones indígenas y afros exigieron coherencia con dicha premisa, demandando espacios de participación directa en la mesa de negociación. A pesar de que algunos líderes étnicos hicieron parte durante el 2014 de las delegaciones de víctimas que viajaron a La Habana para el ciclo de negociación sobre este punto, las mismas víctimas indígenas y afros invitadas declararon que su participación individual era insuficiente y que se requerían espacios con sus organizaciones, para ser escuchadas sus propuestas más allá de ser casos particulares representativos de la violencia. Como menciona un líder indígena entrevistado, "había una cuestión sectorizada y estaban agarrando a unas y otras personas como víctimas, pero no como movimiento, no como colectivo". A su vez, otra lideresa afro asegura: "Hubo participaciones de compañeros y compañeras, pero desde el punto de vista de víctimas, no como organización”.

Al menos cuatro resignificaciones de la noción de víctima fueron movilizadas por las organizaciones afros e indígenas para participar a partir y más allá de esta condición. En primer lugar, una ampliación de la historicidad de la victimización, en una temporalidad que incluye no solo las violencias del conflicto armado, sino también las producidas por la colonización y la esclavización, como quedó reconocido en el capítulo étnico del acuerdo de paz. En palabras de un líder indígena: "En el tema de víctimas, nuestra visión era más amplia, no era solamente afectación específica por el tema del conflicto armado, sino que era el tema de víctima como pueblos indígenas desde la colonización y la invasión”. Aunque esta importante reivindicación sobre la historicidad de la violencia contra las poblaciones indígenas y negras viene consolidándose hace décadas, durante el proceso de incidencia de las organizaciones étnicas fue retomado constantemente como parte de la legitimidad de su participación en las negociaciones y en la puesta en marcha del acuerdo de paz. La segunda reinterpretación fue la reivindicación como 
víctimas colectivas, acentuando la dimensión comunitaria de los daños causados por la guerra. Desde su postura era insuficiente escuchar de forma disgregada algunas personas víctimas que hicieran parte de grupos étnicos, sino se tenía en cuenta la dimensión colectiva que ha implicado el daño causado por la guerra en las comunidades. Parte de este planteamiento logró ser consignado en los Decretos Ley 4633 y 4635 de 2011, dictados en desarrollo de la Ley 1448 o Ley de Víctimas y Restitución de Tierras de 2011, gracias a la participación de las organizaciones, y donde se contemplan para el caso de las comunidades negras e indígenas los daños individuales causados por el conflicto, pero a su vez los daños colectivos, los daños individuales con efecto colectivo y los daños al territorio, entre otros (Rodríguez y Orduz, 2012).

Articulado a estos elementos, un tercer énfasis fueron las particularidades sociales y culturales para reconocerse como víctimas diferenciales, es decir, como colectividades con prácticas y cosmovisiones diferentes a las de la sociedad mayoritaria. La reivindicación misma del territorio como víctima, con reconocimiento legal en la Ley 1448 del 2011, ha sido desde hace años una apuesta de indígenas y afros para denunciar los impactos socio-ecológicos y cosmogónicos que la guerra ha causado (Ruiz, 2017). En palabras de un líder afrocaucano, el planteamiento del movimiento afro y el indígena era: "No estás hablando de cualquier tipo de víctimas, estás hablando de víctimas colectivas que son millones de personas, que tienen una cultura particular”. Dentro de la lógica estatal, lo que se conoce como enfoque étnico diferencial dentro del marco de las políticas multiculturales, ha permitido en cierta medida el reconocimiento de las particularidades culturales indígenas y afros en el accionar institucional, sin embargo, no deja de suscitar críticas por sus limitaciones para solucionar problemas estructurales en el marco de la configuración neoliberal del Estado (Chávez, 2011; Villa, 2011). Una última resignificación fue su reconocimiento como víctimas constructoras de paz, acentuando experiencias, procesos organizativos y alternativas creadas frente a la violencia ocurrida en sus territorios. Afros e indígenas exigieron 
que no solo fueran escuchados sus testimonios de victimización, sino también sus propuestas como colectividades políticas con argumentos y experiencias de paz más allá del punto mismo de víctimas. Las palabras de un líder indígena entrevistado son esclarecedoras al respecto:

Pensaban que solamente participáramos en el tema de víctimas, pero que no participáramos en el tema de territorio, de reforma rural, en el tema de los cultivos, de participación política. Nada más pensaban allá que lo fundamental, el punto nuestro, era solamente trabajar el tema de víctimas, tanto FARC como Gobierno.

Esta apuesta va más allá del rol que se le asigna convencionalmente a las víctimas en los procesos de diálogo social luego de periodos de violencia: fuente testimonial ejemplarizante, relato de un pasado tortuoso o narrativa memorial (Blair, 2005). Las apuestas étnicas enfatizaban sus propias experiencias territoriales de paz, como las guardias indígenas y cimarronas, los procesos de educación intercultural, los sistemas de justicia propios y la protección de los territorios de las economías legales e ilegales vinculadas a la guerra, exigiendo entonces una participación que fuera transversal a todos los puntos que involucraba el acuerdo.

Un cuarto momento antagónico, que potencializó fuertemente las demandas étnicas, fue el ejercicio de articulación política con la creación de la Comisión Étnica. Creada a inicios del 2016, este espacio congregó organizaciones indígenas y afrodescendientes de nivel regional y nacional, con el fin específico de incidir directamente en la mesa de negociación. La legítima autorrepresentación que simbolizaba la Comisión fue un núcleo articulador, afirmándose a sí misma como "la instancia nacional, autónoma, plural, decisoria, participativa, permanente y de autorepresentación [énfasis agregado] de los pueblos y organizaciones indígenas y afrodescendientes que trabajan por la construcción de la paz" (Comisión Étnica, 2016a, p. 381). Aunque existen antecedentes de este diálogo interétnico a nivel nacional en el proceso de la Constituyente de 1991 (Castaño, 2016), esta articulación a largo plazo ha sido un fe- 
nómeno relativamente novedoso para los movimientos indígena y afro. En sí misma, la Comisión Étnica no puede entenderse sin dos factores claves. En primer lugar, los procesos locales y regionales que la han posibilitado, incluso a pesar de las tensiones y conflictividades territoriales (Duarte, 2015). En este sentido, el norte del Cauca es un referente, pues las organizaciones han conformado desde hace años escenarios de diálogo y relacionamiento intercultural como el Consejo Territorial Interétnico e Intercultural del Norte del Cauca, del cual algunos líderes participaron en la Comisión Étnica y apoyaron la redacción del capítulo étnico del acuerdo de paz. En segundo lugar, la Comisión Étnica es también resultado de espacios más amplios de articulación y convergencia de movimientos sociales, como lo han sido en diferentes momentos el Congreso de los Pueblos, el Paro Nacional Agrario del 2013 y la Minga Agraria, Campesina, Étnica y Popular (Vega, 2019).

Teniendo en cuenta que "la práctica de la articulación consiste [...] en la construcción de puntos nodales que fijan parcialmente el sentido" (Laclau y Mouffe, 1987, p. 130), las organizaciones negras e indígenas establecieron como puntos nodales la defensa del territorio como fuente de vida y comunalidad, la relectura de la victimización y su apuesta por construir paz protegiendo los derechos alcanzados. En palabras de los líderes y lideresas entrevistadas, la articulación de la Comisión Étnica es un ejemplo de "hermanamiento político", donde no se desconocen las diferencias entre los movimientos, pero se prioriza la búsqueda de objetivos comunes: "Somos historias distintas, quizás lógicas políticas distintas, niveles de fortaleza político-organizativo distinto, [...] pero también éramos conscientes de que la única oportunidad era trabajar juntos” (líder afrodescendiente entrevistado).

Finalmente, la quinta dinámica de antagonismo hace referencia al conjunto de acciones de movilización, diplomacia y presión que indígenas y afros realizaron, y que fueron potencializadas en los últimos meses de la negociación. En este punto nos interesa señalar al menos cuatro repertorios de acción colectiva, entendiéndolos como ejercicios co- 
lectivos, sedimentados históricamente, compartidos y elegidos de manera relativamente deliberada para plantear reivindicaciones políticas (Tilly, 2002). Los cuatro repertorios fueron: una presencia directa en La Habana para buscar el diálogo con los negociadores, comisiones de diplomacia internacional y de cabildeo nacional, acciones mediáticas para visibilizar la situación, y finalmente la movilización tanto en acto como en potencia. Varios líderes afros e indígenas buscaron durante los últimos meses de la negociación reuniones con las delegaciones de las FARC y el Gobierno en La Habana, donde expusieron la necesidad de concretar unas audiencias para discutir las propuestas étnicas. Mediante reuniones bilaterales entre miembros de la Comisión y los equipos negociadores, en las cuales encontraron una mayor receptividad a la discusión con los delegados de la guerrilla, indígenas y afros manifestaron la necesidad de transversalizar el enfoque étnico en todos los puntos del acuerdo y establecer audiencias con las organizaciones para ser escuchados. Otro grupo de líderes encabezaron acciones de diplomacia internacional, principalmente en Estados Unidos con actores políticos afroamericanos. A mediados del 2015, varios líderes afros del conPA habían realizado un viaje a Estados Unidos para movilizar apoyos frente a la necesidad de ser escuchados en el proceso de paz. Posteriormente, un líder afro recuerda: "Cuando creamos la Comisión Étnica creamos una comisión para Estados Unidos de cuatro compañeros, dos afros y dos indígenas [...], y ese mismo día nos fuimos cuatro para Cuba”. La diplomacia internacional - liderada en gran parte por el movimiento afro- fue según varios líderes entrevistados, un factor importante para abrir espacios de diálogo en La Habana: “La relación con los procesos afroamericanos que tenía el movimiento afro fue uno de los temas claves que no hay que desconocer" (líder indígena entrevistado).

La presión mediática jugó un papel igualmente relevante. Dado que actualmente no es posible pensar los movimientos sociales y las acciones colectivas sin su dimensión global-internacional, tampoco es posible dejar de lado las estrategias mediáticas y virtuales con las cuales se posicionan las reivindicaciones políticas contemporáneas (Pleyers, 2018). 
Con la presión del avance de los diálogos sin la efectiva recepción de las preocupaciones étnicas a pesar de las reuniones informales y de la consolidación de un documento de propuesta, las organizaciones étnicas utilizaron los medios de comunicación y las redes sociales para denunciar la posible exclusión. Un líder indígena recuerda: "El tema mediático fue clave porque era desde comunicados, Twitter, Facebook, rueda de prensa, era presionar y decir: vean, defensores de derechos humanos, país, mundo, entérense que nos van a dejar por fuera”. Sin duda, las marchas y movilizaciones fueron un repertorio clave. Ya en el Paro Nacional Agrario del 2013 algunas organizaciones étnicas habían posicionado sus demandas de participación, y en octubre del 2015 el CONPA realizó una movilización en Bogotá bajo el lema “Otra vez sin nosotros” para denunciar la exclusión de los acuerdos de La Habana.

Pero en últimas, la mayor incidencia se logra con la Minga de Resistencia por la Vida: un conjunto de marchas, bloqueos y asambleas realizadas entre el 30 de mayo y el 13 de junio de 2016, ocurridas principalmente en el norte del Cauca. Parte de lo acordado con el Gobierno luego del levantamiento del paro fue el compromiso de realizar unas audiencias en La Habana para escuchar directamente a las organizaciones étnicas. En palabras de un líder afrocaucano entrevistado: "Quizás más de lo que se avanzó en el capítulo étnico lo ganamos en la carretera, en la minga de junio de 2016, ahí le ganamos al Gobierno que se reuniera con la Comisión Étnica”. Dichas audiencias se realizaron el 26 y 27 de junio de 2016; en ellas las organizaciones expusieron sus preocupaciones y posteriormente hicieron entrega formal de un documento de propuestas. La tensión volvió a aumentar ante el silencio de las FARC y el Gobierno para discutir e incluir dichas propuestas étnicas en el acuerdo final, así como ante la información de un próximo cierre de las negociaciones y de la firma del acuerdo. Nuevamente, a través de diferentes comunicados y en diversos medios de comunicación, las organizaciones indígenas y afros denunciaban una inminente exclusión, llamando a próximas movilizaciones y bloqueos, de no ser reconocidos. Por ejemplo, la Comisión Étnica emitió un comunicado donde declaraban: 
"Estamos en alerta y en preparativos para un paro nacional por la paz" (2016b, p. 3). Ante la presión, líderes de la Comisión Étnica fueron llamados para reunirse en La Habana con delegados de los negociadores, logrando finalmente acordar el capítulo étnico en la última semana antes de firmar el histórico acuerdo de paz. Este hecho demuestra que tanto en acto como en potencia, la movilización social es significada por los mismos actores como un repertorio de acciones fundamentales para la consecución de espacios de diálogo social con el Gobierno y las FARC.

\section{El Norte del Cauca: territorializar los antagonismos}

En su conjunto, las acciones colectivas étnicas implicaron repertorios desde diferentes niveles (local, regional, nacional e internacional) e involucraron diversos actores, lo que hemos denominado como diálogos sociales rizomáticos. Más que actos calculados y mecánicamente dispuestos, nos interesa resaltar que indígenas y afros posicionaron significados que sintetizan las históricas tensiones de sus movimientos sociales tanto con el Estado como con las insurgencias. Las dinámicas antagónicas que hemos analizado hasta el momento, y que fueron claves para ampliar los marcos del diálogo social sobre la paz, deben ser vistas más allá de estrategias de contención de los proyectos políticos de las élites o de reacciones a la coyuntura política de las negociaciones de La Habana. En un sentido más amplio, las organizaciones étnicas interpelaron el significado hegemónico de la paz que se construía desde La Habana, a partir de sus propias tradiciones y repertorios de resistencia, pero recreándolo para hacer frente a la indiferencia. Como resultado, el capítulo étnico consigna en sí mismo los puntos neurálgicos sobre los cuales las organizaciones indígenas y afros tenían dudas, especialmente respecto a la autonomía, los territorios colectivos y la adopción del enfoque étnico que asegurara la pertinencia de las acciones a lo largo de la implementación del acuerdo en los territorios. Estas razones llevan a que las organizaciones indígenas y afros, así como los líderes que estuvieron directa o indirectamente involucrados, vean como un 
logro histórico el acuerdo de paz, pero especialmente el capítulo étnico. Esta significación, recurrente en las entrevistas realizadas, surge de tres razones: por el contenido mismo del capítulo, por el proceso de incidencia-articulación y por haber logrado una participación directa en la mesa como un "tercer actor" (Vega, 2019). Sin lugar a dudas, este logro no hubiera sido alcanzado sin la puesta en marcha del conjunto de acciones colectivas que potencializaron el antagonismo étnico y que involucró diferentes repertorios, escalas y actores. En palabras de un líder afro entrevistado:

La incidencia internacional, yo no niego eso, fue muy importante. Pero el otro $50 \%$ y quizás más de lo que se avanzó en el capítulo étnico lo ganamos en la carretera, en la minga de junio de 2016, ahí le ganamos al Gobierno que se reuniera con la Comisión Étnica, que iba a habilitar la audiencia en La Habana. [...] Un relato sobre el capítulo étnico tiene que hablar sobre esas dos grandes estrategias: la incidencia y la movilización, empujando al mismo tiempo la necesidad de las cosas, apoyando los esfuerzos de construcción conceptual.

Las dinámicas antagónicas que hemos reconstruido tienen dos características de base. En primer lugar, se configuran a partir de procesos históricos anteriores a la mesa de negociación entre las FARC y el Gobierno, con una historicidad anclada a tradiciones de resistencia más amplias. Sin embargo, no son una aplicación mecánica de acciones colectivas estandarizadas y creadas en el pasado. Por el contrario, son una historicidad en acto, con reinterpretaciones y emergencias como las ocurridas alrededor de la noción de víctima y del proceso mismo de articulación que creó la Comisión Étnica. En segundo lugar, los repertorios de acciones colectivas involucraron estrategias que oscilaron permanentemente entre la esfera local, regional, nacional e internacional. En cada nivel, las acciones de diferentes actores sociales, étnicos y no étnicos, fueron claves para movilizar las demandas y reivindicaciones, así como para presionar a las FARC y en particular al Gobierno en favor de una participación orgánica en la mesa. Desde nuestra perspectiva, en ambos 
pilares y a lo largo de todo el proceso de incidencia, el norte del Cauca, sus liderazgos y procesos organizativos, tuvieron un papel central y un peso importante en la consecución del capítulo étnico. En otras palabras, este territorio es un nodo de resistencia clave para el movimiento étnico, entre otras por territorializar la acción colectiva, por las tradiciones de resistencia allí configuradas, y a la vez por el entramado de relaciones interétnicas que ha posibilitado. Según un líder afro:

El norte del Cauca fue determinante para que hubiera capítulo étnico porque se fue a La Habana, porque se estuvo en la jugada de construir los contenidos, porque se estuvo en la incidencia, a nivel internacional, y porque finalmente en el cuerpo a cuerpo, en la carretera, eso se ganó.

Nos interesa señalar ciertos aspectos importantes para argumentar la idea del norte del Cauca como nodo del antagonismo, toda vez que dichos aspectos ayudan a nutrir nociones más amplias y generativas de los diálogos rizomáticos por la paz. Por una parte, los entramados relacionales interétnicos que se han configurado en el norte del Cauca son un antecedente y un potencializador de la articulación política de la Comisión Étnica. Entendemos dichos entramados relacionales interétnicos como el conjunto de conexiones que desde hace siglos se tejen en el Cauca entre la gente indígena y negra no solo a nivel político-organizativo, sino también a nivel de parentescos, territorialidades compartidas e intercambios culturales. Aunque dichos entramados no están exentos de tensiones y conflictividades, especialmente por aspiraciones territoriales (Duarte, 2015; Trujillo, 2015), su potencialidad política se ha hecho evidente en procesos interétnicos e interculturales como el mismo Consejo Territorial Interétnico e Intercultural del Norte del Cauca y otros espacios de diálogo interétnico más locales como la Escuela Interétnica e Intercultural Benicio Flor, del municipio de Suárez, y demás procesos comunitarios en ciertas zonas como El Naya. En palabras de una lideresa indígena: "Hemos venido desarrollando unas dinámicas autónomas en los territorios, unas dinámicas de acercamiento entre los pueblos indígenas y el pueblo negro, prueba de ello es la realidad que 
hay en el norte del Cauca”. A su vez, las organizaciones étnicas del departamento y los liderazgos que allí se han construido jugaron un papel relevante a lo largo de la incidencia en los diálogos de paz no solo en escenarios regionales, sino también a nivel nacional y en La Habana:

Para el capítulo étnico, de acá se movió gente a meterle y a jugar, gente de ACONC y PCN, gente de la ACIN metida en la parte indígena fuertemente y bueno, eso si uno mira en la construcción, en la presión directa en la habana. (Líder afro entrevistado).

como se mencionó, una herramienta clave de presión para lograr la audiencia en La Habana, en junio del 2016, fueron los bloqueos y marchas que tuvieron como epicentro la vía Panamericana en su tramo por el departamento del Cauca. Como lo recuerda un líder afro: “Aquí mismo en Santander [de Quilichao] le ganamos la audiencia al Gobierno, de que la audiencia la iba a ver, que se iban a abrir los espacios y nosotros lo ganamos en la movilización”. Desde hace muchos años las movilizaciones en la Panamericana han sido una forma de territorialización de las luchas no solo del Cauca sino del suroccidente del país, tanto para las organizaciones indígenas como para afros y campesinos que han buscado visibilizar sus demandas y negociar sus reivindicaciones con los diferentes gobiernos. Para muchas comunidades y organizaciones, dichas movilizaciones y mingas en la Panamericana han definido la localidad de sus luchas ante el escenario nacional, una localidad que es un vínculo social territorializado, en últimas una "delimitación de una sociabilidad anclada sobre una base territorial” (Merklen y Pleyers, 2011, p. 30). Las organizaciones del Cauca y particularmente del norte del departamento, tanto por su tradición de resistencia como por la capacidad de liderazgo y de movilización en términos políticos, jugaron un rol fundamental a lo largo de los años que implicó este proceso de antagonismo democrático para participar en el acuerdo de paz. Prácticamente todos los repertorios de acción colectiva identificados tuvieron un correlato o una territorialización de la lucha en el norte del Cauca, donde indígenas y afros han liderado desde hace décadas alternativas al 
conflicto armado y procesos autónomos de construcción de paz, en un contexto altamente riesgoso para las comunidades y los líderes.

\section{A modo de cierre-apertura}

A lo largo del artículo hemos intentado realizar una reconstrucción crítica e interpretativa de las dinámicas antagónicas que permitieron a las organizaciones afros e indígenas hacer visibles sus apuestas étnicas por la paz durante el proceso de negociación entre las FARC y el Gobierno. Consideramos que este ejercicio de volver sobre lo caminado nos permite enriquecer, a partir de los aprendizajes identificados, las posibilidades de diálogos sociales más amplios y generativos sobre la construcción de paz no solo en el ámbito nacional, sino también en lo regional y lo local. La experiencia étnica en el acuerdo de paz, en sus tensiones internas así como en sus limitaciones y posibilidades, nos permite reflexionar sobre el papel de los antagonismos, contestatarios pero a la vez dialogantes, para ampliar los márgenes discursivos y prácticos de la construcción de paz. La concreción del capítulo étnico en el acuerdo final entre el Estado y la guerrilla fue producto de un largo proceso de interpelación a las nociones sobre la paz que se iba configurando en La Habana. Gracias a complejas articulaciones organizativas (locales, regionales y nacionales), una potente resignificación de la idea de víctima y la puesta en marcha de diferentes acciones colectivas más allá de los espacios formales definidos por la mesa de negociación, las organizaciones étnicas lograron hacerse escuchar.

Las dinámicas antagónicas que establecieron, buscaron ser un contrapeso al discurso hegemónico sobre la paz que se construía en La Habana. En su sentido gramsciano y en sus reinterpretaciones posmarxistas, el concepto de hegemonía señala el carácter no fijo de los significantes, la apertura permanente de lo social y los antagonismos que emergen por la construcción de los significados. Las prácticas hegemónicas son finalmente suturas, articulaciones discursivas en las cuales sectores o grupos sociales dominantes logran aglutinar ciertos 
significados y significantes (Laclau y Mouffe, 1987). Dichos sectores, para nuestro caso particular el Estado y las FARC, buscan presentar sus propios objetivos "como aquellos que hacen posible la realización de los objetivos universales de la comunidad” (Laclau, 2004, p. 55), como lo puede ser la paz. En cierta medida, desde los diálogos de La Habana se fueron posicionando discursos hegemónicos sobre la paz en la larga lucha semántica y política por su significado, buscando fijar los términos y contenidos de tan esquivo y polisémico concepto, con el fin de legitimar los acuerdos. Indudablemente las luchas por el sentido de la “paz” en Colombia no comienzan ni terminan allí, pero los diálogos de La Habana abren un nuevo capítulo, que aunque potente y renovador, puede ser ampliado y nutrido críticamente. En este texto hemos examinado justamente cómo el antagonismo étnico a los consensos políticos entre las FARC y el Gobierno, su lucha por la autorrepresentación y la necesidad de garantizar sus derechos frente a potenciales afectaciones, marcaron las agendas étnicas.

Estos años han implicado no solo una lucha semántica por la paz, por su significado y por su contenido, sino una lucha por las implicaciones prácticas y por la performatividad que dichos consensos tienen sobre los territorios y las comunidades. Sin duda, una parte importante de las disputas semánticas y materiales por la paz por parte de indígenas y afros se centra, justamente, en la defensa de los territorios como factor determinante para la garantía de los derechos colectivos. Dentro del discurso hegemónico gubernamental, la noción de paz territorial fue configurándose como una apuesta por desplegar la institucionalidad estatal en las zonas más golpeadas por la guerra atendiendo a sus particularidades, en un esfuerzo para "institucionalizar el territorio” como señalan algunos autores (Jiménez-Martín, 2016; Bautista, 2017). Desde nuestra perspectiva, han sido las mismas organizaciones y comunidades indígenas y afrodescendientes quienes desde hace décadas han pensado la relación entre paz y territorio al menos desde dos aristas. Primero, reflexionando y buscando activamente territorios de paz, rechazando la violencia y construyendo alternativas comunitarias 
pertinentes en cada contexto. En segundo lugar, las organizaciones étnicas han construido procesos de paz territorial contrahegemónicos, en los cuales cuestionan el papel del Estado como el actor legítimo y monopólico en un escenario de transición. Para muchos de los líderes entrevistados, los procesos comunitarios indígenas y afros son en sí mismos una muestra de construcción de paz territorial: experiencias locales y regionales para enfrentar diferentes actores armados, disminuir el impacto de la guerra, rechazar las diferentes formas de violencia, transformar las condiciones de exclusión y proponer alternativas de protección de los territorios. Incluso, algunos líderes aseguran que el capítulo étnico aportó decisivamente a la dimensión territorial del acuerdo de paz:

El capítulo étnico lo que le aporta a la arquitectura de la paz es la dimensión de lo territorial en la implementación, ese no era un acuerdo territorial, el capítulo étnico territorializa los acuerdos y concreta cómo lo vamos a implementar. (Lideresa afro).

La experiencia de los antagonismos indígenas y afros sobre las negociaciones de paz permite evidenciar cómo ciertos sectores de la sociedad civil se reafirman como actores políticos y agentes de transformación durante los procesos de transición política, así como evidencia la importancia del disenso democrático y propositivo para ampliar los horizontes del diálogo social. A partir de los análisis propuestos, quisiéramos extender algunos elementos de esta experiencia que permiten enriquecer la noción de diálogos sociales reticulares. Por este concepto hemos entendido un ejercicio de interlocución entre diferentes actores sociales, con apuestas relativamente articulables, basados en conversaciones y acciones entretejidas desde diferentes nodos. ${ }^{5}$ Como hemos sostenido en el caso de las organizaciones afros e indígenas, la articulación es un factor clave en la configuración de este tipo de diálogos.

5 Estos nodos son, en últimas, puntos de convergencia: territorial, política, discursiva, organizativa, etc. 
Más que una expresión de una esencia subyacente, la articulación es el resultado de una lucha, de una construcción política que parte de una pluralidad democrática decidida a construir conjuntamente a partir de elementos disímiles (Laclau y Mouffe, 1987), en un continuo de equilibrios inestables (Gramsci, 2013). Puesto que los procesos de articulación son contingentes, dinámicos e inacabados, deben ser vistos como una "forma de conexión que puede crear una unidad de dos elementos diferentes, bajo determinadas condiciones. Es un enlace que no necesariamente es determinado, absoluto y esencial por todo el tiempo" (Hall, 2010, p. 85). En el caso de la Comisión Étnica, esta no puede entenderse sin comprender por lo menos cuatro dimensiones articulatorias: el proceso histórico-temporal que la subyace; la imbricación dinámica de procesos organizativos locales, regionales y nacionales; el papel fundamental de ciertos liderazgos que posibilitaron dicha confluencia; y el contexto que favoreció oportunidades políticas para concretar la incidencia.

Las articulaciones políticas implican la construcción en y desde las diferencias, que en el caso estudiado se potencian desde diálogos interculturales, donde diversos conocimientos — sin desconocer las conflictividades políticas y epistémicas - son reconocidos, puestos en discusión e interpelados hacia una ecología de saberes y hacia una traducción intercultural, para retomar las afortunadas acepciones propuestas por Boaventura de Sousa Santos (2009; 2019). Este autor se pregunta justamente: “¿Cómo articular y mantener un diálogo entre diferentes saberes que, en algunas situaciones, se basan en culturas diferentes?” (2019, p. 41). Los diálogos interétnicos que generó la Comisión Étnica son un ejemplo interesante, como lo menciona un líder indígena entrevistado:

Lo que se da a nivel nacional en el caso de la Comisión Étnica y todo el trabajo ha sido muy bonito, a pesar de la diferencia y las discusiones, pero creo que se ha logrado poder dar a conocer una visión de que afros e indígenas podemos convivir y aportarle mucho al país. 
Aunado a esto, otra característica de lo que llamamos diálogos sociales reticulares es la posibilidad de una acción multiescalar, toda vez que hilvana los planos locales, regionales, nacionales e incluso internacionales, que sin evadir las tensiones y contradicciones cumplen un papel estratégico en diferentes momentos. Al mismo tiempo, el reto de dichas acciones a múltiples niveles no es solo complementarse, sino evitar cerrar los espacios de interlocución y diálogo con otros actores. Por eso, una característica igualmente relevante es la puesta en marcha de acciones contestarias pero dialogantes, que abran espacios más allá de los mecanismos formales de interlocución. Probablemente ese sea también uno de los aprendizajes de los procesos organizativos del Cauca, los cuales han buscado articular la movilización y la negociación, como lo menciona un líder afro del norte del departamento: "Las organizaciones étnicas del norte del Cauca han tenido un rol fundamental y es en la movilización, cuando se aprietan las cosas a nivel nacional el Cauca responde con movilización y esa movilización del Cauca abre el diálogo”.

En últimas, este tipo de diálogos sociales, en sus apuestas y formas reticulares y antagónicas, se inscriben en una crítica de la representación, desconfiando de la idea bajo la cual el poder se debe delegar a otros, quienes están supuestamente legitimados para decidir. Al interpelar la legitimidad exclusiva del Gobierno y de las FARC para hablar sobre la paz y las implicaciones de esta para las comunidades étnicas, las organizaciones afros e indígenas vitalizan la apuesta de construir diálogos amplios y democráticos, poniendo en cuestionamiento las prácticas hegemónicas de corte autoritario que esconde la representación en el sentido convencional (Laclau y Mouffe, 1987). Lejos de ser una barrera para la construcción de paz, los antagonismos democráticos, basados en el enriquecimiento de los términos y de los participantes que dialogan, son vitales para dinamizar las transformaciones sociales, políticas y económicas necesarias para salir de la violencia. Sin estar exentos de paradojas y tensiones internas, los liderazgos y organizaciones étnicas lograron un "hermanamiento" político en el cual articularon sus 
demandas, lograron hacer explícita la defensa de sus derechos en los acuerdos, resignificaron la noción de víctima como constructores de paz y plantearon propuestas para territorializar la implementación de lo pactado, desde una perspectiva más incluyente y pertinente para las comunidades. Por supuesto, sus apuestas de paz no comienzan ni terminan con las negociaciones de La Habana, y así como amplificaron los marcos de los diálogos por la paz seguirán construyendo, como lo han hecho en muchas regiones de Colombia, alternativas a la violencia desde la autonomía y la defensa de los territorios.

\section{Referencias}

Bautista, Sandra Carolina. (2017). Contribuciones a la fundamentación conceptual de paz territorial. Ciudad Paz-ando, 10(1), 100-110.

Benjamin, Walter. (2009). La dialéctica del suspenso. Fragmentos de la historia. Santiago: lom Ediciones.

Blair, Elsa. (2005). Memorias de violencia, espacio, tiempo y narración. Controversia, (185), 9-19.

Braconnier, Laetitia. (2018). Los derechos propios de los pueblos étnicos en el Acuerdo de Paz de agosto de 2016. Derecho del Estado, (40), 113-126.

Brett, Roddy. (2017). La voz de las víctimas en la negociación: Sistematización de una experiencia. Bogotá: Programa de las Naciones Unidas para el Desarrollo. Consultado el 10 de septiembre de 2018, de undp: https://www.undp.org/ content/dam/colombia/docs/Paz/undp-co-victimas2016ajustado-2017.pdf

Brett, Roddy. (2018). The Role of the Victims' Delegations in the Santos-FARC Peace Talks. En Vincent Druliolle y Roddy Brett (Eds.), The Politics of Victimhood in Post-conflict Societies. Comparative and Analytical Perspectives. Cham: Palgrave-MacMillan.

Caballero-Fula, Henry. (2016). Acuerdos de La Habana y territorialidad indígena. Una mirada desde el departamento del Cauca. Bitácora Urbano Territorial, 26(2), 95-102. 
Castaño, Christian. (2016). Participación, reivindicaciones políticas y sociales de los raizales en la Asamblea Nacional Constituyente de 1991. Revista Cuadernos del Caribe, (22), 57-70.

Castillejo, Alejandro. (2017). Introducción. Dialécticas de la fractura y la continuidad: elementos para una lectura crítica de las transiciones. En Alejandro Castillejo (Comp.), La ilusión de la justicia transicional: perspectivas críticas desde el sur global. Bogotá: Universidad de los Andes.

Chávez, Margarita (Comp.). (2011). La multiculturalidad estatalizada. Indígenas, afrodescendientes y configuraciones de estado. Bogotá: Instituto Colombiano de Antropología e Historia.

Comisión Étnica para la Paz y la Defensa de los Derechos Territoriales. (2016a). Comunicado 002. En Sheila Gruner, Melquiceded Blandon, Jader Gómez y Charo Mina-Rojas (Eds.). Des/dibujando el pais/aje. Aportes para la paz con los pueblos afrodescendientes e indígenas: territorio, autonomía y buen vivir. Medellín: Poder Negro Editores.

Comisión Étnica para la Paz y la Defensa de los Derechos Territoriales. (2016b). Comunicado 003. Consultado el 12 de marzo de 2019, en onIC: http:// www.onIC.org.co/comunicados-ONIC/1410-comunicado-oficial-comisionetnica-para-la-paz-y-la-defensa-de-los-derechos-territoriales

Consejo Nacional de Paz Afrocolombiano [ConPA]. (2017). Agenda de paz afrocolombiana. Bogotá: Agencia para el Desarrollo Internacional/Oficina en Washington para Asuntos Latinoamericanos. Consultado el 15 de noviembre de 2018, en afrodescolombia: http://www.afrodescolombia. org/wp-content/uploads/2017/07/Agenda_de_paz_conPA.Final-ilovepdfcompressed.pdf.

Cruz, Edwin. (2017). Caminando la palabra. Movilizaciones sociales en Colombia (2010-2016). Bogotá: Ediciones Desde Abajo.

Druliolle, Vincent y Brett, Roddy. (2018). Introduction: Understanding the Construction of Victimhood and the Evolving Role of Victims in Transitional Justice and Peacebuilding. En Vincent Druliolle y Roddy Brett (Eds.), The Politics of Victimhood in Post-conflict Societies. Comparative and Analytical Perspectives. Cham: Palgrave-MacMillan. 
Duarte, Carlos. (2015). Desencuentros territoriales: la emergencia de los conflictos interétnicos e interculturales en el departamento del Cauca. Bogotá: Instituto Colombiano de Antropología e Historia.

Gatti, Gabriel y Martínez, María. (2017). Presentación: El ciudadano-víctima. Notas para iniciar un debate. Revista de Estudios Sociales, (59), 8-14.

Gatti, Gabriel. (Ed.). (2017). Un mundo de víctimas. Barcelona: Anthropos.

Gramsci, Antonio. (2013). Antología (Manuel Sacristán, Trad.). Madrid: Ediciones Akal.

Hall, Stuart. (2010). Sin garantías. Trayectorias y problemáticas en estudios culturales. Quito: Envión Editores.

Jiménez-Martín, Carolina. (2016). Justicia territorial para la construcción de la paz. Bitácora Urbano Territorial, 26(2), 59-66.

Karatzogianni, Athina y Robinson, Andrew. (2010). Power, Resistance and Conflict in the Contemporary World. Social movements, networks and hierarchies. Nueva York: Routledge.

Kroc Institute for International Peace Studies. (2018). Estado efectivo de implementación del Acuerdo de Paz en Colombia. Informe 2: Diciembre 2016Mayo 2018. Bogotá: University of Notre Dame.

Laclau, Ernesto y Mouffe, Chantal. (1987). Hegemonía y estrategia socialista. Hacia una radicalización de la democracia. Madrid: Siglo XXI Editores.

Laclau, Ernesto. (2004). Identidad y hegemonía: el rol de la universalidad en la constitución de lógicas políticas. En Judith Butler, Ernesto Laclau y Slavoj Žižek, Contingencia, hegemonía, universalidad. Diálogos contemporáneos de la izquierda. Buenos Aires: Fondo de Cultura Económica.

McadamMcAdam, Doug; Tarrow, Sidney y Tilly, Charles. (2003). Dynamics of contention. Nueva York: Cambridge University Press.

Merklen, Denis y Pleyers, Geoffrey. (2011). La localisation des mouvements sociaux. Cahiers des Amériques Latines, (66), 25-37.

Navia-Lame, José. (2015). La fuerza del ombligo: crónicas del conflicto en territorio nasa. Popayán: Universidad del Cauca. 
Oficina del Alto Comisionado para la Paz. (2018). Biblioteca del proceso de paz con las farc-ep. Tomo VII. Los mecanismos e instancias de participación de la mesa de conversaciones y la construcción de paz desde los territorios. Bogotá: Presidencia de la República/Oficina del Alto Comisionado para la Paz.

Organización Nacional Indígena de Colombia [ONIC]. (2015). Agenda Nacional de Paz de los Pueblos Indígenas de Colombia. Consultado el 20 de mayo de 2019 en ONIC: https://www.onIC.org.co/canastadesaberes/118-cds/publicaciones/conflicto-armado-y-paz/1820-agenda-nacional-de-paz-de-lospueblos-indigenas

Organizaciones afrocolombianas en el Foro Político de Desarrollo Agrario Integral. (2016). Que nos oigan en La Habana: la metodología no puede violar los derechos. En Sheila Gruner, Melquiceded Blandon, Jader Gómez y Charo Mina-Rojas (Eds.). Des/dibujando el pais/aje. Aportes para la paz con los pueblos afrodescendientes e indígenas: territorio, autonomía y buen vivir. Medellín: Poder Negro Editores.

Peñaranda, Daniel. (2015). Guerra propia, guerra ajena. Conflictos armados y reconstrucción identitaria en los Andes colombianos. El movimiento armado Quintín Lame. Bogotá: Centro Nacional de Memoria Histórica/Instituto de Estudios Políticos y Relaciones Internacionales.

Pleyers, Geoffrey. (2018). Movimientos sociales en el siglo XXI. Perspectivas y herramientas analíticas. Buenos Aires: Clacso.

Rodríguez, César y Orduz, Natalia (2012). La consulta previa: dilemas y soluciones. Lecciones del proceso de construcción del decreto de reparación y restitución de tierras para pueblos indígenas en Colombia. Bogotá: Centro de Estudios de Derecho, Justicia y Sociedad, Dejusticia.

Ruiz, Daniel. (2017). El territorio como víctima. Ontología política y las leyes de víctimas para comunidades indígenas y negras en Colombia. Revista Colombiana de Antropología, 53(2), 85-113.

Santos, Boaventura de Sousa. (2009). Una epistemología del Sur. La reinvención del conocimiento y la emancipación social. México: Consejo Latinoamericano de Ciencias Sociales/Siglo XXI Editores.

Santos, Boaventura de Sousa. (2019). El fin del imperio cognitivo. La afirmación de las epistemologías del Sur. Madrid: Editorial Trotta. 
Tilly, Charles. (2002). Repertorios de acción contestataria en Gran Bretaña 1758-1834. En Mark Traugott (Comp.), Protesta social, repertorios y ciclos de la acción colectiva. Barcelona: Editorial Hacer.

Trujillo, Daniela. (2015). Impactos de la racionalidad multicultural: conflictividad interétnica en el norte del Cauca. Revista Controversia, (205), 64-94.

Vega, Rodolfo. (2019). El capítulo étnico del Acuerdo de Paz de La Habana. La historia del tercer actor de la negociación (Tesis de maestría inédita). Pontificia Universidad Javeriana. Bogotá.

Villa, William. (2011). El movimiento social indígena colombiano: entre autonomía y dependencia. En Ana Cecilia Betancur (Ed.), Movimientos indígenas en América Latina. Resistencia y nuevos modelos de integración. Copenhague: International Work Group for Indigenous Affairs.

Villarraga, Álvaro. (2015). Biblioteca de la Paz 1980-2013. Los procesos de paz en Colombia, 1982-2014. Bogotá: Fundación Cultura Democrática. 